\title{
The Impact of Thyroid Nodule Size and Fine-Needle Aspiration Biopsy Result on the Risk of Malignancy in the Patients Who Underwent Thyroidectomy
}

\author{
Hwibin Im, Yu-Young Park, Jae-Gu Cho, Seung-Kuk Baek, \\ Soon-Young Kwon, Kwang-Yoon Jung, and Jeong-Soo Woo \\ Department of Otorhinolaryngology-Head and Neck Surgery, College of Medicine, Korea University, Seoul, Korea
}

\section{갑상선 결절의 크기와 수술 전 세침흡인검사 결과가 갑상선절제술을 받은 환자의 악성 진단에 미치는 영향}

임휘빈 · 박유영 · 조재구 · 백승국 · 권순영 · 정광윤 · 우정수

고려대학교 의과대학 이비인후-두경부외과학교실

\author{
Received February 14, 2017 \\ Revised March 7, 2017 \\ Accepted March 11, 2017 \\ Address for correspondence \\ Jeong-Soo Woo, MD, PhD \\ Department of Otorhinolaryngology- \\ Head and Neck Surgery, \\ Guro Hospital, \\ College of Medicine, \\ Korea University, \\ 148 Gurodong-ro, Guro-gu, \\ Seoul 08308, Korea \\ Tel $+82-2-2626-3187$ \\ Fax $+82-2-868-0475$ \\ E-mail diakonos@korea.ac.kr
}

Background and Objectives The frequency of ultrasonography and cytological examinations for thyroid nodules has increased. But the efficacy of fine needle aspiration biopsy varies according to the size of the nodules. The study aimed to identify the effect of thyroid nodule size on malignancy.

Subjects and Method The medical records of patients who underwent total or hemithryoidectomy in a single tertiary hospital were retrospectively analyzed. A total of 204 nodules were obtained from 193 patients who underwent fine needle aspiration biopsy before thyroid surgery. After each nodule was classified by size, the results of the fine needle aspiration test and risk of the final diagnosis were evaluated using logistic regression analysis.

Results The average size of 204 Bethesda class 2 (benign) nodules was $2.99 \mathrm{~cm}$, which was larger than those of other classes $(p<0.05)$. In the final histopathologic diagnosis, there was a difference in size between benign $(2.41 \mathrm{~cm})$ and malignant nodules $(1.23 \mathrm{~cm})(p<0.05)$. In addition, a logistic regression analysis showed that the nodules below $2.0 \mathrm{~cm}$ in size showed an odd ratio of 7.81, compared to the nodules larger than $2.0 \mathrm{~cm}(p<0.05)$.

Conclusion According to the results of this study, malignancy was higher when the thyroid nodule was less than $2 \mathrm{~cm}$. Therefore, a careful observation is needed for nodules less than $2 \mathrm{~cm}$ for which fine needle aspiration biopsy would be recommended. Conversely, it is necessary to reconsider the diagnostic surgery for nodules larger than $2 \mathrm{~cm}$.

Korean J Otorhinolaryngol-Head Neck Surg 2017;60(6):308-13

Key Words Biopsy · Fine-needle $\cdot$ Thyroid gland · Thyroid neoplasms · Thyroid nodule.

\section{서 론}

갑상선 암은 한국에서 가장 흔한 암이다. 2012년 발표된

This is an Open Access article distributed under the terms of the Creative Commons Attribution Non-Commercial License (http://creativecommons.org/licenses/by-nc/4.0) which permits unrestricted non-commercial use, distribution, and reproduction in any medium, provided the original work is properly cited.
대한 암 학회의 자료에 따르면 갑상선 암은 국내에서 발생한 암 중 약 $19.6 \%$ 를 차지한다. 또한 10 만 명당 62.5 명의 갑상선 암 유병률은 세계적으로 높은 수치에 속한다. 하지만 갑상선 암은 그 유병률이 높아짐에도 불구하고 이로 인한 사망률은 이전과 큰 변화가 없고, ${ }^{2)}$ 이에 대한 진단과 치료는 보존적인 방향으로 변하고 있다. ${ }^{3}$ 
한편 세침흡인검사(fine needle aspiration)는 갑상선 결절 을 평가하는 데 점점 더 중요한 검사가 되고 있다.5) 그러나 갑 상선 결절을 세침흡인검사로 진단할 때 결절의 크기에 따라 악성 진단율과 진단의 위음성율의 차이를 보이기도 한다. ${ }^{6.7)}$ 반대로, 다른 연구들에서는 갑상선 결절의 크기가 세침흡인 검사의 결과에 영향을 주지 않는다고 결론 짓기도 한다. ${ }^{8-10)}$ 갑상선 결절의 크기에 따른 악성 진단율이 변한다는 연구들 의 결론에 근거하여, 몇몇 의료진들은 갑상선 결절의 크기를 통해 진단적 갑상선 수술을 계획하기도 한다. ${ }^{6,7)}$

한국에서는 국민건강보험공단의 암 검진(National Cancer Screening Program in Korea) 대상에 갑상선 암이 포함되어 있지 않으나, 많은 병원들에서 갑상선 암 검진을 위한 초음 파를 다른 국가에 비해 낮은 가격에 제공하고 있다. ${ }^{11)}$ 이로 인해 1962 2009년 사이 한국에서는 $1 \mathrm{~cm}$ 이하의 작은 갑상 선 암이 진단되는 비율이 6.1 43.1\%까지 증가하였다. ${ }^{12}$ 낮은 수가의 검진을 통하여 갑상선 암이 많이 진단되는 이러한 한 국의 의료 환경 속에서 수술 전 갑상선 결절의 크기와 세침흡 인검사를 통해 최종 악성 진단을 예측할 수 있다면 불필요한 수술을 줄이고 환자의 불편을 덜어 줄 수 있을 것이다.

이 연구에서는 최근 갑상선 수술을 받은 환자들의 의무기 록을 후향적으로 분석하여 갑상선 결절의 크기가 수술 전 세 침흡인검사 및 최종 악성 진단에 미치는 영향을 알아보았다.

\section{대상 및 방법}

\section{대 상}

이 연구는 본원 임상시험심의위원회의 승인(IRB No. KUGH16304-002)을 받아 진행된 연구이며, 2010년 4월부터 2012년 5월까지 이비인후-두경부외과에서 갑상선 엽절제술 혹은 전절제술을 시행 받은 환자를 대상으로 의무기록을 후 향적으로 분석하였다. 이 기간 동안 총 196 명의 환자가 갑상 선 수술을 진행하였고, 이 환자들의 갑상선 결절 204개에 대 해 수술 전 세침흡인검사를 시행하였다. 환자들 중 완결 갑 상선 절제술(completion thyroidectomy)의 목적으로 수술 받 았던 환자 3 명을 제외하여 총 193 명의 환자들이 대상이 되었 다. 갑상선 수술의 결과 총 255 개의 결절의 조직검사 결과가 보고되었으나, 수술 전 세침흡인검사를 시행했던 204개의 갑 상선 결절만 연구에 포함되었고, 수술 결과 추가로 얻어진 51 개의 조직검사 결과는 분석대상에서 제외되었다.

\section{방 법}

환자들의 의무기록에서 세침흡인검사의 세포학적 검사 결 과, 갑상선 결절의 개수, 결절의 크기, 조직학적인 최종 진단
에 대한 데이터를 수집하였다. 갑상선 결절의 크기는 수술 전 시행한 초음파 검사를 통해 측정되었고, 가장 큰 지름을 기 준으로 평가하였다. 갑상선 결절 중 실제로 수술 전 세침흡인 검사를 시행한 것을 연구 대상으로 하였고, 수술 후 조직학적 검사상 발견되는 추가적인 결절은 모두 제외하였다. 하나의 결절에 대하여 두 가지의 다른 세침흡인검사 결과가 발생하 였을 때는 좀 더 가능성이 높은 것을 채택하였다.

갑상선 세침흡인검사의 약 $90.2 \%$ (204개 중 184개)는 숙련 된 본원 내분비내과 전문의 또는 영상의학과 두경부 분과 전 문의가 진행하였으며, 모두 초음파를 이용하여 원하는 결절 에 27-gauge 바늘 끝이 위치한 것을 확인한 후 진행하였다. 이렇게 얻어진 검체에 대한 세포학적인 분석은 5 년 이상의 숙 련된 경력을 가진 본원의 병리학 전문의가 시행하였다. 20 개 의 검체는 타 병원에서 시행한 세침흡인검사로 얻어졌으며, 이 중 18 개는 마찬가지로 숙련된 병리학 전문의가 재분석하였 다. 나머지 2 개의 검체는 검사를 시행했던 타원의 검체 판독 결과지를 참조하였다.

검체의 세포학적인 분석은 2009년 미국 국립암센터에서 발 표한 The Bethesda System for Reporting Thyroid Cytopathology에 따라 6가지 범주로 나타냈다. Class 1은 nondiagnostic, class 2 는 benign, class 3 은 atypia of undetermined significance 또는 follicular lesion of undetermined significance, class 4는 suspicious for follicular neoplasm 또는 follicular neoplasm, class 5 는 suspicious for malignant disease, class 6은 malignant 결과를 나타낸다.

Benign 결과를 나타내는 class 2 를 음성 결과로 판단하였 고, class 3 부터 class 6 까지를 악성의 가능성이 있는 양성 결과 로 두고 세침흡인검사의 민감도, 특이도, 음성예측도, 양성예 측도를 구하였으며, 위음성율은 세침흡인검사상 양성 결과 를 보인 결절이 수술로 얻어진 최종 조직검사 결과가 갑상선 암으로 진단된 경우로 정의하였다. 이분형 로지스틱 회귀분 석을 통하여 갑상선 결절의 크기와 세침흡인검사 결과가 악성 진단에 어떤 영향을 주는지에 대한 통계학적 분석을 시행하 였다. 통계학적 유의수준은 $p$-value 0.05 이하로 하였으며 통 계적 검증을 위해 IBM SPSS statistic version 22.0(IBM Corp., Armonk, NY, USA)을 이용하였다.

\section{결 과}

갑상선 수술 전 세침흡인검사를 시행하였던 총 193 명의 환 자를 대상으로 분석한 결과 여성은 153 명(79.3\%), 남성은 40명 (20.7\%), 성비는 3.8:1이었다. 평균 연령(표준편차)은 49.4세 (12.4세), 중간값은 49세(14.0 83.0)로 나타났다. 평균적인 갑 
상선 결절의 크기(표준편차)는 $1.5 \mathrm{~cm}(1.2)$ 로 측정되었으며 총 204개의 갑상선 결절 중, Bethesda class 1은 5개(2.5\%), class 2는 21개(10.3\%), class 3은 21개(10.3\%), class 4는 12개 (5.9\%), class 5는 30개(14.7\%), class 6은 115개(56.4\%)로 나 타났다. 최종 조직검사 결과 악성 결절은 162 개, 양성 결절은 42 개였다. 162 개의 악성 결절 중 155 개의 결절(95.7\%)이 papillary carcinoma였고, 7개(4.3\%)는 follicular carcinoma였다. 42 개의 양성 결절 중 가장 많은 것은 nodular hyperplasia(n= 31, 73.8\%)로 나타났다(Table 1).

Table 1. Demographic and clinical characteristics of patients

\begin{tabular}{lc}
\hline \multicolumn{1}{c}{ Characteristics } & Number of patients $(\%)$ \\
\hline Age $($ mean \pm SD $)$ & $49.4( \pm 12.4)$ years \\
Sex & $40(20.7)$ \\
Male & $153(79.3)$ \\
Female & $1.5( \pm 1.2) \mathrm{cm}$ \\
Nodule size $($ mean \pm SD) & \\
Bethesda class & $5(2.5)$ \\
I & $21(10.3)$ \\
II & $21(10.3)$ \\
III & $12(5.9)$ \\
IV & $30(14.7)$ \\
V & $115(56.4)$ \\
VI & \\
Final histopathology & $42(20.6)$ \\
Benign & $31(73.8)$ \\
Nodular hyperplasia & $6(14.3)$ \\
Follicular adenoma & $1(2.4)$ \\
Hashimoto thyroiditis & $1(2.4)$ \\
Riedel's thyroiditis & $2(4.8)$ \\
Normal thyroid & $162(79.4)$ \\
Malignant & $7(4.3)$ \\
Follicular carcinoma & $155(95.7)$ \\
Papillary carcinoma &
\end{tabular}

Table 2에서 각 결절을 크기별로 분석하였는데, $1.0 \mathrm{~cm}$ 이 하의 결절은 99 개(48.5\%), $1.0 \mathrm{~cm}$ 초과 $2.0 \mathrm{~cm}$ 이하의 결절은 64 개(31.4\%), $2.0 \mathrm{~cm}$ 초과 $3.0 \mathrm{~cm}$ 이하의 결절은 19 개(9.3\%), $3.0 \mathrm{~cm}$ 초과 $4.0 \mathrm{~cm}$ 이하의 결절은 11 개 $(5.4 \%), 4.0 \mathrm{~cm}$ 초과하 는 결절은 11 개(5.4\%)였다. 세침흡인검사 결과별 결절의 크기 를 비교해 보았을 때, class 2에서만 평균 $2.99 \mathrm{~cm}$ 로 다른 class 에 비해 크게 나타났다(one-way ANOVA, $p<0.05$ ). 최종 조 직 진단에서도 양성으로 진단된 경우 $(2.41 \mathrm{~cm})$ 와 악성으로 진단된 경우 $(1.23 \mathrm{~cm})$ 의 크기 차이가 나는 것을 확인할 수 있 다(nonparametric test, Mann-Whitney 검정, $p<0.05$ ). 또 한 크기에 따라 나눈 그룹 간의 수술 전 세침흡인검사 결과의 분포도 서로 다르게 나타났다. $1.0 \mathrm{~cm}$ 이하의 결절과 $1.0 \mathrm{~cm}$ 초과 $2.0 \mathrm{~cm}$ 이하의 결절, $2.0 \mathrm{~cm}$ 초과 $3.0 \mathrm{~cm}$ 이하의 결절에 서는 Bethesda class 6 의 결과(각각 63.6, 57.8, 52.6\%)가 가 장 많았다. $3.0 \mathrm{~cm}$ 초과 $4.0 \mathrm{~cm}$ 이하의 결절에서는 class 2 와 class 6 의 비율이 $27.3 \%$ 로 같게 나타났으며, $4.0 \mathrm{~cm}$ 를 초과 하는 그룹에서는 Bethesda class 2의 결과(63.6\%)가 가장 많 이 나타났다.

Table 3에서는 결절의 크기에 따른 수술 전 세침흡인검사 결 과와 최종 악성 진단의 odds ratio를 나타내었다. 결절의 크기 가 $3.0 \mathrm{~cm}$ 초과 $4.0 \mathrm{~cm}$ 이하인 결절과 $4.0 \mathrm{~cm}$ 초과하는 결절 은, $1 \mathrm{~cm}$ 이하의 결절보다 수술 전 세침흡인검사 결과 Bethesda class 6을 나타낼 odds값이 각각 0.238( $p=0.047), 0.123(p=$ 0.010)으로 나타났다. 즉, 갑상선 결절의 크기가 클수록 수술 전 세침흡인검사상 악성 결과가 나올 가능성이 떨어진다. 또 한 갑상선 결절의 크기가 최종 악성 진단에 미치는 영향을 알아보기 위해 시행한 로지스틱 회귀 분석의 결과에서는 1.0 $\mathrm{cm}$ 이하의 갑상선 결절을 reference variable로 하였을 때 2.0 $\mathrm{cm}$ 를 초과한 결절의 odds ratio는 $1.0 \mathrm{~cm}$ 이하의 결절보다 모두 유의하게 작은 것을 볼 수 있다.

Table 2. FNA class and final histopathology results according to size

\begin{tabular}{|c|c|c|c|c|c|c|}
\hline \multirow{2}{*}{ Test } & \multicolumn{5}{|c|}{ Size group } & \multirow{2}{*}{$\begin{array}{l}\mathrm{n}(\text { mean } \\
\text { size } \pm S D)\end{array}$} \\
\hline & $1(\leq 1 \mathrm{~cm})$ & $2(1-2 \mathrm{~cm})$ & $3(2-3 \mathrm{~cm})$ & $4(3-4 \mathrm{~cm})$ & $5(>4 \mathrm{~cm})$ & \\
\hline \multicolumn{7}{|l|}{ FNA class, n (\%) } \\
\hline 1 & $1(1.0)$ & $2(3.1)$ & $1(5.3)$ & $1(9.1)$ & $0(0)$ & $5(1.84 \pm 0.98)$ \\
\hline 2 & $5(5.1)$ & $3(4.7)$ & $3(15.8)$ & $3(27.3)$ & $7(63.6)$ & $21(2.99 \pm 2.01)$ \\
\hline 3 & $7(7.1)$ & $10(15.6)$ & $1(5.3)$ & $2(18.2)$ & $1(9.1)$ & $21(1.58 \pm 1.12)$ \\
\hline 4 & $3(3.0)$ & $4(6.3)$ & $4(21.1)$ & $1(9.1)$ & $0(0)$ & $12(1.83 \pm 0.97)$ \\
\hline 5 & $20(20.2)$ & $8(12.5)$ & $0(0)$ & $1(9.1)$ & $1(9.1)$ & $30(1.12 \pm 1.00)$ \\
\hline 6 & $63(63.6)$ & $37(57.8)$ & $10(52.6)$ & $3(27.3)$ & $2(18.2)$ & $115(1.21 \pm 0.88)$ \\
\hline \multicolumn{7}{|c|}{ Histopathology, n (\%) } \\
\hline Benign & $10(10.1)$ & $11(17.2)$ & $7(36.8)$ & $7(63.6)$ & $7(63.6)$ & $42(2.41 \pm 1.61)$ \\
\hline Malignant & $89(89.9)$ & $53(82.8)$ & $12(63.2)$ & $4(36.4)$ & $4(36.4)$ & $162(1.23 \pm 0.98)$ \\
\hline Total, n (\%) & $99(48.5)$ & $64(31.4)$ & $19(9.3)$ & $11(5.4)$ & $11(5.4)$ & \\
\hline
\end{tabular}

FNA: fine needle aspiration 
Table 3. Univariate odds ratio of Bethesda class 6 and final malignant result according to size

\begin{tabular}{|c|c|c|c|c|}
\hline \multirow{2}{*}{ Nodule size } & \multirow{2}{*}{ Odds ratio* } & \multirow{2}{*}{ p-value } & \multicolumn{2}{|c|}{$95 \% \mathrm{Cl}$ for odds ratio } \\
\hline & & & Lower & Upper \\
\hline \multicolumn{5}{|c|}{ Odds ratio of Bethesda class 6 result } \\
\hline Size $(<1)$ & 1.000 & & & \\
\hline Size $(1-2)$ & 0.822 & 0.558 & 0.427 & 1.582 \\
\hline Size $(2-3)$ & 0.694 & 0.482 & 0.251 & 1.921 \\
\hline Size $(3-4)$ & 0.238 & 0.047 & 0.058 & 0.979 \\
\hline Size $(>4)$ & 0.123 & 0.010 & 0.025 & 0.604 \\
\hline \multicolumn{5}{|c|}{ Odds ratio of final malignant result } \\
\hline Size $(<1)$ & 1.000 & & & \\
\hline Size $(1-2)$ & 0.541 & 0.192 & 0.215 & 1.360 \\
\hline Size $(2-3)$ & 0.193 & 0.005 & 0.062 & 0.601 \\
\hline Size $(3-4)$ & 0.064 & 0.000 & 0.016 & 0.258 \\
\hline Size $(>4)$ & 0.064 & 0.000 & 0.016 & 0.258 \\
\hline
\end{tabular}

*odds ratio for reference variables are represented as 1.000. Cl: confidence interval

Table 4. Univariate odds ratio of final malignant result (analyzed based on $2 \mathrm{~cm}$ )

\begin{tabular}{|c|c|c|c|c|}
\hline \multirow[t]{2}{*}{ Nodule size } & \multirow{2}{*}{$\begin{array}{l}\text { Odds } \\
\text { ratio* }\end{array}$} & \multirow[t]{2}{*}{ p-value } & \multicolumn{2}{|c|}{$\begin{array}{l}95 \% \mathrm{Cl} \text { for } \\
\text { odds ratio }\end{array}$} \\
\hline & & & Lower & Upper \\
\hline Analyzed based on $2 \mathrm{~cm}$ & & 0.000 & 3.546 & 17.208 \\
\hline Size $(\leq 2)$ & 7.812 & & & \\
\hline Size $(>2)$ & 1.000 & & & \\
\hline \multicolumn{5}{|l|}{ Each FNA class group } \\
\hline FNA class 2 & & 0.295 & 0.299 & 53.468 \\
\hline Size $(\leq 2)$ & 4.000 & & & \\
\hline Size $(>2)$ & 1.000 & & & \\
\hline FNA class 3 & & 0.916 & 0.127 & 9.943 \\
\hline Size $(\leq 2)$ & 1.125 & & & \\
\hline Size $(>2)$ & 1.000 & & & \\
\hline FNA class 4 & & 0.417 & 0.211 & 42.624 \\
\hline Size $(\leq 2)$ & 3.000 & & & \\
\hline Size $(>2)$ & 1.000 & & & \\
\hline FNA class 5 & & 0.059 & 0.887 & 821.790 \\
\hline Size $(\leq 2)$ & 27.000 & & & \\
\hline Size $(>2)$ & 1.000 & & & \\
\hline FNA class 6 & & 0.996 & 0.000 & \\
\hline Size $(\leq 2)$ & 115391060 & & & \\
\hline Size $(>2)$ & 1.000 & & & \\
\hline
\end{tabular}

*odds ratio for reference variables are represented as 1.000 . $\mathrm{Cl}$ : confidence interval, FNA: fine needle aspiration

Table 4는 $2.0 \mathrm{~cm}$ 를 기준으로 하여 로지스틱 회귀 분석을 재시행하여 얻은 결과로써, $2.0 \mathrm{~cm}$ 이하의 결절은 $2.0 \mathrm{~cm}$ 초 과하는 결절보다 7.812(3.546 17.208)의 odds값을 나타냈다. 즉, $2.0 \mathrm{~cm}$ 이하의 결절에서 악성 진단이 의미 있게 상승되어 있었다. 또한, 수술 전 세침흡인검사의 세포학적 검사 결과에 따른 Bethesda class로 갑상선 결절을 그룹화한 후 각 그룹 별로 크기에 따른 악성도가 $2 \mathrm{~cm}$ 를 기준으로 어떻게 달라지 는지를 살펴보았다. 각 class별로 로지스틱 회귀분석을 시행
한 결과 $2 \mathrm{~cm}$ 기준으로 악성도가 더 높아지는 class는 보이지 않았다. Bethesda class 5 인 suspicious for malignant disease 에서는 27.000(0.887 821.790)의 odds값을 보였으나, 통계적 으로 의미를 갖지는 않았다 $(p=0.059)$.

갑상선 수술 후 최종 조직검사 결과 악성으로 진단된 검체 는 162개(79.4\%)였으며, 세침흡인검사를 시행했던 결절이 갑 상선 수술 후 조직학적 검사에 따라 실제 악성으로 진단되는 비율은 Bethesda class 1 부터 6까지 차례대로 40.0, 14.2, 52.4, $33.3,93.3,99.1 \%$ 로 나타났다. Class 1을 제외한 199 개의 갑상 선 결절을 대상으로 분석한 수술 전 세침흡인검사의 민감도 는 $98.1 \%$, 특이도는 $46.2 \%$ 였으며, 양성예측도는 $88.2 \%$, 음성 예측도는 $85.7 \%$ 였다. 이 연구에서 위음성 결과는 총 3 건이 있 었다.

\section{고 찰}

본 연구를 통하여 갑상선 결절의 크기와 세침흡인검사 및 최종 조직검사의 악성도의 상관관계를 알아보았다. 이 연구 결과 갑상선 수술을 받은 환자의 최종 조직검사 결과는 결절 의 크기가 $2.0 \mathrm{~cm}$ 를 기준으로 악성도의 차이를 보이고 있었 다. 최근 갑상선 결절의 크기와 악성 진단과의 상관관계에 대 한 다양한 연구들이 있으며, 저자 등에 의해 시행된 본 연구 결과는 Magister 등 ${ }^{13)}$ 의 연구와 유사한 결과를 내고 있다. 본 연구의 결과 $2.0 \mathrm{~cm}$ 이하의 갑상선 결절에서 Bethesda class 6 의 결과가 가장 많았으며, $4.0 \mathrm{~cm}$ 이상의 갑상선 결절 에서 시행한 세침흡인검사의 결과에서는 Bethesda class 2 의 양성 결과가 $63.6 \%$ 로 의미 있게 상승되어 있었다. 이는 $4 \mathrm{~cm}$ 를 기준으로 세침흡인검사의 악성도가 증가한다는 다른 연 구들의 결론과는 상반되는 결론을 나타내고 있다. ${ }^{714-16)}$ 오히 
려 결절의 크기와 악성 진단과의 상관관계가 뚜렷하지 않다는 연구들 ${ }^{8,17)}$ 이나 0.5 0.9 cm의 갑상선 결절의 악성도가 $4.0 \mathrm{~cm}$ 이상의 크기를 갖는 갑상선 결절보다 높은 악성도를 보인다는 Shrestha 등 ${ }^{18)}$ 의 연구 결과와 유사하다고 할 수 있다.

$4.0 \mathrm{~cm}$ 초과의 크기를 갖는 결절에서 Bethesda class 2의 세포학적 검사 결과가 가장 높게 나온 것은 Hammad 등히이 연구한 메타분석의 결과와 비슷하다. 이 연구에서 저자들은 3.0 이상 $5.9 \mathrm{~cm}$ 이하의 결절에서는 악성도가 증가하지만, 6.0 $\mathrm{cm}$ 이상의 큰 갑상선 결절에서 악성도가 낮아진다는 결론을 내었다. 한편, 본 연구에서 Bethesda class별로 군을 나눈 후 $2.0 \mathrm{~cm}$ 를 기준으로 악성도를 분석하였을 때 $2.0 \mathrm{~cm}$ 이하의 그룹과 $2.0 \mathrm{~cm}$ 이상의 그룹의 악성도 차이를 보이는 class는 없었다. Bethesda class 5 에서 $2.0 \mathrm{~cm}$ 이하의 그룹이 27.0 의 odds를 보였으나 유의확률 0.059 로 통계학적인 의미를 갖지 는 못하였다. 이는 낮은 위음성율과도 관계가 있을 것으로 생 각된다. 수술을 고려하고 시행하였던 환자들을 대상으로 하 였기 때문에 수술 전 세침흡인검사 소견이 어느 정도 비정상 적이었을 것이며, 이렇게 비정상의 세포검사 소견을 보인 환자 중 실제로 양성으로 진단된 환자의 수는 적을 것으로 보인다.

본 연구에서는 숙련된 세침흡인검사의 시행과 정확한 세포 학적 분석을 통해 3 건의 적은 위음성 결과를 나타내었다. 연 구에 포함된 양성 결절의 수가 낮은 것을 고려한다면, 양성 결 절의 검체 수를 더 증가시킬 경우 위음성율은 더 낮아질 것으 로 생각된다. 낮은 위음성율은 세침흡인검사의 악성 진단에 대한 효용성을 뒷받침하는 결과이며, 세침흡인검사 결과를 통해 최종진단을 미루어 짐작할 수 있다는 가정을 가능하게 한다. 본 연구에서도 세침흡인검사 결과는 악성 진단에 큰 영 향을 주는 단일 인자임이 분명해 보인다.

이 연구의 한계점으로 단일 삼차병원에서 시행한 연구인 점 과 이로 인해 대규모의 연구가 이루어지지 못한 점을 생각할 수 있다. 이는 최근 이루어지고 있는 다기관의 대규모 환자를 대상으로 하는 연구들이 이러한 점을 보완해 줄 수 있을 것 이다. 또한 환자의 의무기록을 후향적으로 분석한 연구라는 것에서 선택 오류 등이 발생할 수 있는데, 특히 수술을 진행 한 환자의 갑상선 결절만을 분석하였기 때문에 갑상선 결절 들의 악성(class 6)이나 악성이 의심되는(class 5) 세침흡인검 사 결과의 비율이 높다. 더불어 수술을 진행하지 않은 갑상선 결절에 대한 정보를 알 수 없다는 한계점이 있다. 갑상선 암 검진이 빈번하게 이루어지는 한국에서 시행한 연구이므로 갑 상선 결절의 크기가 비교적 다른 연구에 비해 작게 발견 되었 을 가능성도 있는데, 실제로 본 연구의 갑상선 결절의 평균 크기는 $1.5 \mathrm{~cm}$ 로 Magister 등 $^{13)}$ 의 연구 또는 Shrestha 등 ${ }^{18)}$ 의 연구의 갑상선 결절의 평균 크기보다 더 작았다. 마지막으
로, 수술 전 세침흡인검사를 통한 검체의 세포학적인 분석의 결과로 Bethesda class를 이용하는데, 이는 병리학 전문의 사 이에서 이견이 발생할 수 있는 여지가 있다.

이러한 한계점에도 본 연구는 합의점이 아직 이루어지지 않은 갑상선 결절의 크기와 악성도에 대한 주제에서 의미 있 는 결과를 도출한 또 하나의 연구로서 의미가 있는 것으로 생 각한다. 특히 빈번한 갑상선 암 검진이 이루어져 갑상선의 조 기 발견 또는 과잉 진단의 문제가 대두되는 한국의 의료 환경 을 반영한 연구로써 의미가 있는 것으로 보인다.

\section{REFERENCES}

1) Jung KW, Won YJ, Kong HJ, Oh CM, Cho H, Lee DH, et al. Cancer statistics in Korea: incidence, mortality, survival, and prevalence in 2012. Cancer Res Treat 2015;47(2):127-41.

2) International Agency for Research on Cancer. GLOBOCAN 2012: estimated cancer incidence, mortality and prevalence worldwide in 2012 [cited 2016 Aug 18]. Available from: http://globocan.iarc.fr.

3) Yi KH. The revised 2016 Korean Thyroid Association guidelines for thyroid nodules and cancers: differences from the 2015 American Thyroid Association guidelines. Endocrinol Metab 2016;31(3):373-8.

4) Chen JC, Pace SC, Chen BA, Khiyami A, McHenry CR. Yield of repeat fine-needle aspiration biopsy and rate of malignancy in patients with atypia or follicular lesion of undetermined significance: the impact of the Bethesda system for reporting thyroid cytopathology. Surgery 2012;152(6):1037-44.

5) Marqusee E, Benson CB, Frates MC, Doubilet PM, Larsen PR, Cibas ES, et al. Usefulness of ultrasonography in the management of nodular thyroid disease. Ann Intern Med 2000;133(9):696-700.

6) Giles WH, Maclellan RA, Gawande AA, Ruan DT, Alexander EK, Moore FD Jr, et al. False negative cytology in large thyroid nodules. Ann Surg Oncol 2015;22(1):152-7.

7) Shin JJ, Caragacianu D, Randolph GW. Impact of thyroid nodule size on prevalence and post-test probability of malignancy: a systematic review. Laryngoscope 2015;125(1):263-72.

8) Albuja-Cruz MB, Goldfarb M, Gondek SS, Allan BJ, Lew JI. Reliability of fine-needle aspiration for thyroid nodules greater than or equal to $4 \mathrm{~cm}$. J Surg Res 2013;181(1):6-10.

9) Mehanna R, Murphy M, McCarthy J, O’Leary G, Tuthill A, Murphy MS, et al. False negatives in thyroid cytology: impact of large nodule size and follicular variant of papillary carcinoma. Laryngoscope 2013; 123(5):1305-9.

10) Raj MD, Grodski S, Woodruff S, Yeung M, Paul E, Serpell JW. Diagnostic lobectomy is not routinely required to exclude malignancy in thyroid nodules greater than four centimetres. ANZ J Surg 2012; 82(1-2):73-7.

11) Park SH, Lee B, Lee S, Choi E, Choi EB, Yoo J, et al. A qualitative study of women's views on overdiagnosis and screening for thyroid cancer in Korea. BMC Cancer 2015;15:858.

12) Cho BY, Choi HS, Park YJ, Lim JA, Ahn HY, Lee EK, et al. Changes in the clinicopathological characteristics and outcomes of thyroid cancer in Korea over the past four decades. Thyroid 2013;23(7): 797-804.

13) Magister MJ, Chaikhoutdinov I, Schaefer E, Williams N, Saunders B, Goldenberg D. Association of thyroid nodule size and Bethesda class with rate of malignant disease. JAMA Otolaryngol Head Neck Surg 2015;141(12):1089-95.

14) Carrillo JF, Frias-Mendivil M, Ochoa-Carrillo FJ, Ibarra M. Accuracy of fine-needle aspiration biopsy of the thyroid combined with an evaluation of clinical and radiologic factors. Otolaryngol Head Neck 
Surg 2000;122(6):917-21.

15) Kuru B, Gulcelik NE, Gulcelik MA, Dincer H. Predictive index for carcinoma of thyroid nodules and its integration with fine-needle aspiration cytology. Head Neck 2009;31(7):856-66.

16) Hammad AY, Noureldine SI, Hu T, Ibrahim Y, Masoodi HM, Kandil E. A meta-analysis examining the independent association between thyroid nodule size and malignancy. Gland Surg 2016;5(3):312-7.
17) Parikh PP, Allan BJ, Lew JI. Sex variability of fine-needle aspiration reliability in the diagnosis of malignancy in thyroid nodules $\geq 4 \mathrm{~cm}$. Am J Surg 2013;206(5):778-82.

18) Shrestha M, Crothers BA, Burch HB. The impact of thyroid nodule size on the risk of malignancy and accuracy of fine-needle aspiration: a 10-year study from a single institution. Thyroid 2012;22(12):1251-6. 